\title{
ANALISIS USAHATANI DAN PEMASARAN BERAS PANDANWANGI (STUDI KASUS DI KELOMPOK TANI BANGKIT DESA BABAKAN KARET KECAMATAN CIANJUR KABUPATEN CIANJUR)
}

\author{
Oleh : \\ Asep Saepul Alam**) \\ Muh Heri Khoerudin*)
}

\begin{abstract}
Abstrak
Potensi kabupaten cianjur untuk mengembangkan beras pandanwangi yang memiliki harga jual lebih tinggi dari varietas lainnya serta kendala yang dihadapi oleh beberapa petani mengenai umur tanam yang lebih lama. Saluran pemasaran beras umumnya panjang dan tidak efisien. Penelitian dilakukan di Kelompok Tani Bangkit Desa Babakan Karet Kecamatan Cianjur Kabupaten Cianjur mulai Bulan Mei sampai Juli 2018 dengan tujuan untuk : 1) Menganalisis usahatani beras Pandanwangi di Kelompok Tani Bangkit. 2) Menganalisis saluran pemasaran, fungsi - fungsi pemasaran dan efisiensi pemasaran pada masing - masing lembaga pemasaran beras Pandanwangi di Kelompok Tani Bangkit. Penelitian ini menggunakan teknik purposive sampling dan snowball sampling dalam penentuan tempat dan responden. Hasil penelitian menunjukkan bahwa : 1. Diketahui bahwa untuk varietas Pandanwangi diperoleh nilai $\mathrm{R} / \mathrm{C}$ rasio adalah sebesar 1,87 di dapatkan dari Total Penerimaan sebesar Rp. 12.000.000 lalu dibagi Total Biaya Rp. 6.430 .000 maka di dapatkan Nilai R/C Rasio sebesar 1,87. 2. Saluran pemasaran yang efisien adalah saluran pemasaran II meskipun nilai marginnya lebih kecil dari saluran pemasaran I, dikarenakan permintaan pasar jauh lebih tinggi dari saluran pemasaran I. Petani dan distributor melakukan fungsi - fungsi pemasaran seperti Fungsi Fisik dan Fungsi Pertukaran. Sedangkan Farmer's share yang paling efisien berada di saluran pemasaran II yaitu $73,75 \%$
\end{abstract}

Kata Kunci : Beras Pandanwangi,Usahatani, R/C Rasio, Saluran Pemasaran, Fungsi Pemasaran Marjin Pemasaran, dan Farmer's Share.

\begin{abstract}
Abstrak
Potency of Cianjur regency to develop Pandanwangi rice which has higher selling price than the other varieties and the obstacles faced by some farmers about longer planting time. The marketing channels of rice are generally long and inefficient. The research was conducted at Bangkit Farmer Group, Babakan Karet Village, Cianjur district, Cianjur Regency from May to July 2018 with the aim to: 1) Analyze Pandanwangi rice agribusiness in Bangkit Farmer Group. 2) Analyze marketing channels, marketing functions and marketing efficiency at each Pandanwangi rice marketing agency in Bangkit Farmer Group. This research uses purposive sampling and snowball sampling technique in the determination of place and respondent. The results shows that: 1. It is known that for Pandanwangi variety, $R / C$ ratio of 1.87 was obtained from the Total Revenue of Rp. 12.000.000 and divided by Total Cost of Rp. 6.430 .000 which resulting in $\mathrm{R} / \mathrm{C}$ Ratio value of 1.87. 2. An efficient marketing channel is a marketing channel II even

ANALISIS USAHATANI DAN
PEMASARAN BERAS PANDANWANGI
(STUDI KASUS DI KELOMPOK TANI
BANGKIT DESA BABAKAN KARET
KECAMATAN CIANJUR KABUPATEN
CIANJUR)
\end{abstract}


though its margin value is less than marketing channel I, because market demand is much higher than marketing channel I. Farmers and distributors perform marketing functions such as Physical Function and Exchange Function. While the most efficient Farmer's share is in marketing channel II which is $73.75 \%$.

Keywords : Pandanwangi Rice, Agribusiness, R / C Ratio, Marketing Channels, Marketing Margin, Marketing Functions, and Farmer's Share.

*) Alumni Fakultas Sains Terapan UNSUR

**) Dosen Fakultas Sains Terapan UNSUR

ANALISIS USAHATANI DAN
PEMASARAN BERAS PANDANWANGI
(STUDI KASUS DI KELOMPOK TANI
BANGKIT DESA BABAKAN KARET
KECAMATAN CIANJUR KABUPATEN
CIANJUR)




\section{PENDAHULUAN}

Indonesia adalah negara agraris dimana sebagian besar penduduknya hidup dari hasil bercocok tanam atau bertani, sehingga pertanian merupakan sektor yang memegang peranan penting dalam kesejahteraan kehidupan penduduk Indonesia. Menurut Nuhang (2003) dan Ustriyana (2015), komoditas yang seharusnya dikembangkan dalam rangka ketahanan pangan nasional adalah komoditas yang mempunyai potensi riil yang besar dan diusahakan secara masal oleh masyarakat. Padi merupakan salah satu tanaman pangan yang berpotensi ekonomis untuk dikembangkan. Padi yang menghasilkan beras merupakan tumpuan utama bagi ketahanan pangan nasional. Berdasarkan data hasil Susenas-BPS (survei sosial ekonomi nasional-Badan Pusat Statistik), rata-rata konsumsi beras selama periode 2002-2013 sebesar 1,98 $\mathrm{kg} / \mathrm{kapita} /$ minggu atau setara dengan $103,18 \mathrm{~kg} / \mathrm{kapita} /$ tahun (Susenas-BPS, 2014).

Pemerintah Kabupaten Cianjur berupaya mengembangkan Varietas Unggul Baru seperti Ciherang, IR 64, Cimelati, Sintanur dan Varietas Unggul Lokal seperti padi Varietas Pandanwangi (Dinas Pertanian Kabupaten Cianjur, 2006).

Pemasaran beras Pandanwangi dari tingkat petani hingga konsumen akhir melibatkan berbagai lembaga pemasaran dalam suatu saluran pemasaran. Banyaknya mata rantai saluran pemasaran dari tingkat petani hingga konsumen akhir menyebabkan besarnya perbedaan harga produk yang diterima oleh petani dan harga produk yang dibayarkan oleh konsumen akhir. Dalam hal ini petani sebagai produsen, cenderung untuk menjual beras kepada lembaga pemasaran selanjutnya dari pada mengolahnya secara langsung. (Prima, 2008).

Menurut Rahim dan Hastuti (2008) usahatani merupakan salah satu cara petani untuk mengelola faktor-faktor produksi dengan efektif, efisien dan terus menerus untuk menghasilkan produksi atau input yang tinggi sehingga pendapatan usahataninya meningkat. Menurut Soekartawi (2006) Pendapatan usahatani merupakan selisih antara penerimaan dan semua biaya. Adapun fungsi pendapatan memenuhi kebutuhan sehari-hari dan kebutuhan kegiatan usaha tani selanjutnya.

Pendapatan usaha tani dapat dirumuskan sebagai berikut:

$$
\begin{aligned}
& \mathrm{Pd}=\mathrm{TR}-\mathrm{TC} \\
& \mathrm{TR}=\mathrm{Y} \times \mathrm{Py} \\
& \mathrm{TC}=\mathrm{FC}+\mathrm{VC}
\end{aligned}
$$

dimana :

$$
\begin{aligned}
& \mathrm{Pd}=\text { pendapatan usahatani } \\
& \mathrm{TR}=\text { total penerimaan }(\text { total revenue) } \\
& \mathrm{TC}=\text { total biaya }(\text { total cost }) \\
& \mathrm{FC}=\text { biaya tetap }(\text { fixed cost }) \\
& \mathrm{VC}=\text { biaya variabel }(\text { variabel cost }) \\
& \mathrm{Y}=\text { produksi yang diperoleh }
\end{aligned}
$$

dalam usaha tani

$$
\text { Py }=\text { harga } Y
$$

Definisi pemasaran menurut beberapa para ahli :

1. Saladin (2003) pemasaran adalah suatu sistem total dari kegiatan bisnis yang dirancang untuk merencanakan, menentukan harga mempromosikan dan mendistribusikan barang-barang yang dapat memuaskan keinginan dan mencapai pasar sasaran serta tujuan perusahaan.

2. Kotler (2005) pemasaran adalah proses sosial yang dengan mana individu dan kelompok mendapatkan apa yang mereka butuhkan dan inginkan dengan menciptakan, menawarkan dan secara bebas mempertukarkan produk dan jasa yang bernilai dengan pihak lain.

3. Rahim dan Hastuti (2007) pemasaran pertanian adalah proses aliran komoditas yang disertai perpindahan hak milik dan penciptaan guna waktu, tempat, bentuk, yang dilakukan oleh lembaga-lembaga pemasaran dengan 
melaksanakan salah satu atau lebih fungsi-fungsi pemasaran.

\section{METODE PENELITIAN}

\section{Waktu dan Tempat}

Penelitian dilakukan di Kelompok Tani Bangkit Desa Babakan Karet Kecamatan Cianjur Kabupaten Cianjur. Pemilihan lokasi dilakukan secara sengaja (purposive), dengan pertimbangan bahwa Kelompok Tani Bangkit merupakan salah satu lembaga yang melakukan pemasaran beras Pandanwangi. Penelitian ini dilaksanakan dari bulan Juni sampai dengan Juli 2018.

\section{Responden}

Responden adalah orang yang merespon atau menjawab pertanyaan Variabel Penelitian penelitian baik pertanyaan tertulis maupun lisan (Arikunto, 2006). Untuk mendapatkan informasi dan data yang dibutuhkan, maka dalam pelaksanaan penelitian ini pihak yang dijadikan sebagai responden yaitu petani dan lembagalembaga pemasaran. Metode penentuan responden adalah dengan menggunakan metode snow ball sampling, yaitu teknik penentuan responden dengan menelusuri saluran pemasaran dari perusahaan sampai ke tangan konsumen akhir. Menurut Usman (2009) teknik sampling ini tidak tersedia data jumlah populasi sehingga tidak dapat membuat kerangka sampel. Jumlah responden disesuaikan dengan kriteria yang ditetapkan untuk dijadikan sample penelitian.

Tabel 1.Operasional Penelitian

\begin{tabular}{|c|c|c|c|}
\hline Aspek & Variabel & Sumber Data & Analisis \\
\hline $\begin{array}{l}\text { Gambaran } \\
\text { umum tempat } \\
\text { penelitian }\end{array}$ & $\begin{array}{l}\text { 1. Gambaran umum Kelompok } \\
\text { Tani Bangkit }\end{array}$ & $\begin{array}{l}\text { Primer dan } \\
\text { Sekunder }\end{array}$ & Analisis Deskriptif \\
\hline \multirow{2}{*}{$\begin{array}{l}\text { Analisis } \\
\text { usaha tani }\end{array}$} & 2. Analisis pendapatan usaha tani & Primer & $\begin{array}{l}\text { Penerimaan usaha tani } \\
\text { Biaya usaha tani }\end{array}$ \\
\hline & 3. Analisis efisiensi usaha tani & Primer & $\mathrm{R} / \mathrm{C}$ Rasio \\
\hline \multirow{3}{*}{$\begin{array}{l}\text { Analisis } \\
\text { pemasaran }\end{array}$} & 4. Saluran dan lembaga pemasaran & Primer & Analisis Deskriftif \\
\hline & 5. Fungsi - fungsi pemasaran & Primer & Analisis Deskriftif \\
\hline & 6. Efisiensi pemasaran & Primer & $\begin{array}{l}\text { Analisi Margin } \\
\text { pemasaran dan } \\
\text { keuntungan biaya (B/C) } \\
\text { Analisis Farmer's share }\end{array}$ \\
\hline
\end{tabular}

\section{METODE ANALISIS DATA}

Pengolahan dan analisis data dilakukan secara deskriptif kualitatif dan deskriptif kuantitatif. Analisis deskriptif kualitatif dilakukan untuk mengetahui gambaran tentang usahatani dan pemasaran beras varietas Pandanwangi di Kelompok Tani Bangkit Kecamatan Cianjur, Kabupaten Cianjur. Analisis deskriptif kuantitatif dilakukan dengan menggunakan analisis pendapatan, analisis $\mathrm{R} / \mathrm{C}$ rasio, analisis margin, farmer's share dan rasio keuntungan terhadap biaya pemasaran.

\section{Analisis Pendapatan Usaha Tani}

Metode analisis ini dilakukan dengan menggunakan perhitungan pendapatan usahatani yang meliputi total biaya, penerimaan, dan pendapatan. 
Rumus total biaya, penerimaan, dan pendapatan adalah sebagai berikut:

- Rumus biaya total:

$\mathrm{TC}=\mathrm{TFC}+\mathrm{TVC}$

Keterangan:

$\mathrm{TC}=$ Biaya total

$\mathrm{TVC}=$ Biaya variabel total

TFC $=$ Biaya tetap total

- Rumus Penerimaan

$\mathrm{TR}=\mathrm{P} \times \mathrm{Q}$

Keterangan:

TR $($ Total Revenue $)=$ Penerimaan usaha

$\mathrm{Q}($ Quantity $)=$ Produk yang dihasilkan

$\mathrm{P}$ (Price) $=$ Harga jual produk yang dihasilkan

- Rumus Pendapatan

$\mathrm{Y}=\mathrm{TR}-\mathrm{TC}$

$\mathrm{TR}=\mathrm{P} \times \mathrm{Q}$

$\mathrm{TC}=\mathrm{TFC}+\mathrm{TVC}$

Keterangan:

Y : Yield (Pendapatan)

TR : Total Revenue (Penerimaan Total)

TC : Total Cost (Total Biaya)

$\mathrm{P}$ : Price (Harga)

Q : Quantity (Unit)

TFC : Total Fixed Cost (Biaya Tetap Total)

TVC : Total Variable Cost (Biaya Variabel Total)

\section{Analisis Kelayakan Usaha}

Metode analisis ini dilakukan dengan menggunakan perhitungan $\mathrm{R} / \mathrm{C}$ Ratio yang merupakan perbandingan antara penerimaan (R) dan biaya (C). Perhitungan dengan R/C Ratio digunakan untuk mengetahui kelayakan sebuah usahatani.

\section{Analisis Margin}

Margin pemasaran merupakan perbedaan harga yanga terjadi di tingkat produsen (harga jual) dengan harga ditingkat konsumen (harga beli). Besarnya margin pemasaran dipengaruhi oleh jalur pemasaran komoditas bersangkutan. Margin pemasaran diperoleh dari lembaga pemasaran hasil dari fungsi-fungsi pemasaran, harga penjualan dan harga pembelian disetiap tingkatan lembaga pemasaran mulai dari petani, pengumpul, pedagang besar, pedagang pengecer, dan konsumen.

Perhitungan pemasaran secara sisitematis dapat dirumuskan sebagai berikut:

$$
\begin{aligned}
& \mathbf{M i}=\mathbf{H} \mathbf{j i}-\mathbf{H b i} \\
& \mathbf{M i}=\mathbf{C i}+{ }^{n} \mathbf{i} \\
& \mathrm{Hji}-\mathrm{Hbi}-\mathrm{Ci}+{ }^{n_{i}} \\
& n_{i}=\mathbf{H} j \mathbf{i}-\mathbf{H b i}-\mathbf{C i} \\
& \mathbf{M i}=\sum \mathbf{M i}
\end{aligned}
$$

Dimana :

Mi : Margin pemasaran pada pasar tingkat $\mathrm{ke}-\mathrm{i}(\mathrm{Rp} / \mathrm{kg})$

Hji : Harga penjualan pada pasar tingkat $\mathrm{ke}-\mathrm{i}(\mathrm{Rp} / \mathrm{kg})$

Hbi : Harga pembelian pada pasar tingkat $\mathrm{ke}-\mathrm{i}(\mathrm{Rp} / \mathrm{kg})$

]Ci : Biaya pada tingkat pasar ke$\mathrm{i}(\mathrm{Rp} / \mathrm{kg})$

$\pi$ : Keuntungan pemasaran pada

$$
\begin{aligned}
& \text { i pasar tingkat ke }-\mathrm{i}(\mathrm{Rp} / \mathrm{kg}) \\
& \mathrm{I}: 1,2,3, \ldots . \mathrm{n} \\
& \text { Mi : Total margin pemasaran. }
\end{aligned}
$$

Analisis Rasio Keuntungan dan Biaya (B/C)

$B / C$ rasio merupakan suatu ukuran perbandingan antara hasil penjualan dengan biaya operasional untuk memperoleh ukuran kelayakan usaha. Jika usaha dikatakan layak untuk dilaksanakan maka nilainya lebih dari satu. Namun jika tidak layak maka nilai tersebut yaitu kurang dari satu.

$$
\mathrm{B} / \mathrm{C} \text { ratio } \frac{\text { Hasil Penjualan }}{\text { Biaya Operasional }}
$$

Farmer's share

Dalam membandingkan bagian yang diterima petani (farmer's share) terhadap harga yang dibayar konsumen

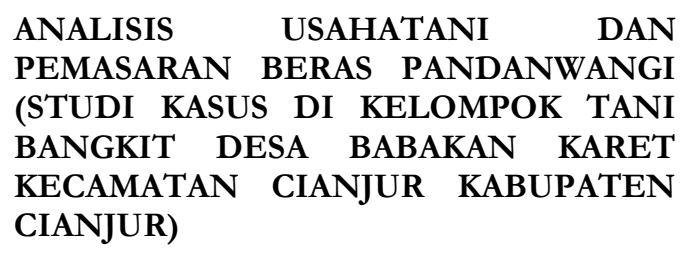


akhir merupakan salah satu indikator yang berguna dalam melihat efisiensi kegiatan pemasaran. Selain daripada itu, jika Farmer's share berhubungan negatif dengan margin pemasaran, artinya semakin tinggi pemasaran sehingga bagian yang akan diperoleh petani (farmer's share) akan semakin rendah.

Rumus untuk menghitung farmer's share adalah :

$$
f s=\frac{p f}{p r} \times 100 \%
$$

Dimana :

$\mathrm{Fs}_{\mathrm{s}}=$ Farmer's share.

Pf $=$ harga di tingkat petani.

Pr= Harga yang dibayar oleh kosumen akhir.

\section{HASIL DAN PEMBAHASAN}

Analisis Usahatani Pandanwangi di Kelompoke Tani Bangkit

Analisis mengenai struktur biaya usahatani merupakan jenis dan besarnya biaya yang harus dipikul oleh seorang petani yang melakukan usahatani varietas Pandanwangi dalam rangka memproduksi sampai menjualnya. Struktur biaya dalam usahatani varietas Pandanwangi dapat diketahui bahwa ada biaya tetap dan ada biaya variabel. Selain biaya ada juga pendapatan dari penerimaan usahatani setelah dilakukannya penjualan beras dari hasil usahatani tersebut, Setelah mendapatkan penerimaan usaha tani maka dapat dihitung $\mathrm{R} / \mathrm{C}$ rasio agar mengetahui layak atau tidaknya usaha tani varietas Pandanwangi ini di jalankan.

Biaya Usahatani Pandanwangi di Kelompok Tani Bangkit

Tabel 2. Struktur Rata-rata Biaya Tetap Usahatani Varietas Pandanwangi Permusim dalam 3000m²

\begin{tabular}{rlrlrrr}
\hline No & $\begin{array}{c}\text { Jenis Biaya } \\
\text { Tetap }\end{array}$ & Volume & Satuan & $\begin{array}{c}\text { Biaya Satuan } \\
(\mathbf{R p})\end{array}$ & Jumlah (Rp) & $\begin{array}{c}\text { Persentase } \\
(\mathbf{0})\end{array}$ \\
\hline 1 & Sewa Tanah & 3000 & $\mathrm{~m}^{2}$ & 1.400 .000 & 140.0000 & 49,78 \\
2 & Pajak Tanah & 3000 & $\mathrm{~m}^{2}$ & 10.000 & 10.000 & 0,36 \\
3 & Pengairan & 3000 & $\mathrm{~m}^{2}$ & 62.500 & 62.500 & 2,22 \\
4 & Alat - alat & & & & \\
A & Cangkul & 2 & Buah & 100.000 & 200.000 & 7,11 \\
B & Arit & 3 & Buah & 50.000 & 150.000 & 5,33 \\
C & Hand Sprayer & 1 & Buah & 570.000 & 570.000 & 20,27 \\
D & Etem & 6 & Buah & 20.000 & 120.000 & 4,27 \\
5 & Sewa Kerbau & 3 & Hari & 100.000 & 300.000 & 10,67 \\
\hline & & \multicolumn{2}{c}{ Total Biaya Tetap } & & & \\
\hline
\end{tabular}

Sumber: Data Primer (Diolah), 2018.

ANALISIS USAHATANI DAN
PEMASARAN BERAS PANDANWANGI
(STUDI KASUS DI KELOMPOK TANI
BANGKIT DESA BABAKAN KARET
KECAMATAN CIANJUR KABUPATEN
CIANJUR)


Tabel 3.Struktur Rata - rata Biaya Variabel Usahatani Varietas Pandanwangi Permusim Dalam 3000M ${ }^{2}$

\begin{tabular}{|c|c|c|c|c|c|c|c|}
\hline No & $\begin{array}{c}\text { Jenis Biaya } \\
\text { Variabel }\end{array}$ & Volume & Satuan & $\begin{array}{c}\text { Biaya } \\
\text { Satuan (Rp) }\end{array}$ & $\begin{array}{c}\text { Jumlah } \\
\text { Hari }\end{array}$ & $\begin{array}{l}\text { Jumlah } \\
\text { (Rp) }\end{array}$ & $\begin{array}{c}\text { Persentase } \\
(\%)\end{array}$ \\
\hline 1 & Pupuk Kandang & 4 & Kwintal & 12.000 & & 48.000 & 1,33 \\
\hline 2 & Benih & 5 & $\mathrm{Kg}$ & 37.500 & & 187.500 & 5,18 \\
\hline 3 & Mol & 4 & Liter & 12.000 & & 48.000 & 1,33 \\
\hline 4 & Vitamin & 30 & Liter & 6.000 & & 180.000 & 4,98 \\
\hline 5 & Karung & 40 & Buah & 2500 & & 100.000 & 2,76 \\
\hline 6 & Tenaga Kerja & & & & & & \\
\hline $\mathrm{a}$ & $\begin{array}{l}\text { Pengolahan } \\
\text { Tanah }\end{array}$ & 4 & $\mathrm{HOK}$ & 50.000 & 3 & 600.000 & 16,59 \\
\hline $\mathrm{b}$ & $\begin{array}{l}\text { Perbaikan } \\
\text { Pematang }\end{array}$ & 2 & $\mathrm{HOK}$ & 50.000 & 1 & 100.000 & 2,76 \\
\hline $\mathrm{c}$ & Cabut Benih & 3 & $\mathrm{HOK}$ & 40.000 & 1 & 120.000 & 3,32 \\
\hline $\mathrm{d}$ & Penanaman & 3 & $\mathrm{HOK}$ & 40.000 & 2 & 240.000 & 6,63 \\
\hline e & Pemupukan & 2 & $\mathrm{HOK}$ & 50.000 & 2 & 200.000 & 5,53 \\
\hline $\mathrm{f}$ & Penyiangan & 3 & $\mathrm{HOK}$ & 40.000 & 2 & 240.000 & 6,63 \\
\hline$g$ & $\begin{array}{l}\text { Penyemprotan } \\
\text { Hama }\end{array}$ & 1 & $\mathrm{HOK}$ & 50.000 & 1 & 50.000 & 1,38 \\
\hline $\mathrm{h}$ & Panen & 7 & $\mathrm{HOK}$ & 40.000 & 4 & 1.120 .000 & 30,96 \\
\hline $\mathrm{i}$ & $\begin{array}{l}\text { Biaya } \\
\text { Menggiling }\end{array}$ & 480 & $\mathrm{Kg}$ & 800 & & 384.000 & 10,62 \\
\hline \multicolumn{6}{|c|}{ Total Biaya Variabel } & 3.617 .500 & 100,00 \\
\hline
\end{tabular}

Sumber: Data Primer (Diolah), 2018.

Tabel 4.Biaya Total Usahatani Varietas Pandanwangi Permusim dalam 3000M²

\begin{tabular}{|c|c|c|c|}
\hline No & Uraian & Nilai & $\%$ \\
\hline 1 & Biaya Tetap & 2.812 .500 & 43,74 \\
\hline 2 & Biaya Variabel & 3.617 .500 & 56,26 \\
\hline & Total Biaya & 6.430 .000 & 100,00 \\
\hline
\end{tabular}

Sumber: Data Primer (Diolah), 2018

Penerimaan Usahatani Pandanwangi di Kelompok Tani Bangkit

Tabel 5.Penerimaan Usahatani Varietas Pandanwangi di Kelompok Tani Bangkit Permusim dalam $3000 \mathrm{M}^{2}$

\begin{tabular}{ccccc}
\hline No & Varietas & $\begin{array}{c}\text { Volume } \\
(\mathbf{k g})\end{array}$ & $\begin{array}{c}\text { Harga Satuan } \\
(\mathbf{R p})\end{array}$ & $\begin{array}{c}\text { Jumlah } \\
(\mathbf{R} \mathbf{p})\end{array}$ \\
\hline 1 & Pandanwangi & 480 & 25.000 & 12.000 .000 \\
\hline
\end{tabular}

Sumber: Data Primer (Diolah), 2018.

Pendapatan Usahatani Pandanwangi di Kelompok Tani Bangkit

Pendapatan usahatani ini penulis hitung berdasarkan total penerimaan dikurangi total biaya. Adapun rincian mengenai pendapatan usahatani varietas Pandanwangi adalah sebagai berikut.
Pendapatan usahatani dapat dirumuskan sebagai berikut:

$$
\begin{aligned}
& \mathrm{Pd}=\mathrm{TR}-\mathrm{TC} \\
& \mathrm{TR}=\mathrm{Y} \times \mathrm{Py} \\
& \mathrm{TC}=\mathrm{FC}+\mathrm{VC}
\end{aligned}
$$

dimana :

$\mathrm{Pd}=$ pendapatan usahatani

$\mathrm{TR}=$ total penerimaan (total revenue) 
dalam usahatani

$$
\begin{aligned}
& \mathrm{TC}=\text { total biaya }(\text { total cost }) \\
& \mathrm{FC}=\text { biaya tetap }(\text { fixed cost }) \\
& \mathrm{VC}=\text { biaya variabel }(\text { variabel cost }) \\
& \mathrm{Y} \quad=\text { produksi yang diperoleh }
\end{aligned}
$$$$
\text { Py }=\text { harga } \mathrm{Y}
$$

Diketahui bahwa untuk pendapatan beras Pandanwangi per musim dalam $3000 \mathrm{M}^{2}$ adalah sebagai berikut : Total Penerimaan Rp. 12.000 .000 dikurangi dengan Total Biaya Rp. 6.430.000 maka diperoleh Pendapatan sebesar Rp. 5.570 .000

\section{Rasio Penerimaan dan Biaya $(\mathrm{R} / \mathrm{C})$}

Pada penelitian ini untuk menganalisis efisiensi usahatani padi dilakukan dengan menggunakan analisis $\mathrm{R} / \mathrm{C}$ rasio. Salah satu ukuran efisiensi adalah penerimaan untuk rupiah yang dikeluarkan (revenue cost ratio atau $\mathrm{R} / \mathrm{C}$ ratio). Analisis Return cost (R/C) ratio merupakan perbandingan (ratio atau nisbah) antara penerimaan dan biaya (Rahim A dan Hastuti DRD, 2008). Analisis R/C ini digunakan untuk mengetahui keuntungan relatif usahatani yang berdasarkan perhitungan finansial, dimana R/C dapat menunjukan besarnya penerimaan yang diperoleh dengan pengeluaran satu satuan biaya.

Menurut Soekartawi (2006) bahwa

$\mathrm{R} / \mathrm{C}$ adalah perbandingan antara penerimaan dan biaya. Secara sistematis, hal ini dapat dituliskan sebagai berikut:

$$
\begin{aligned}
& \mathrm{a}=\mathrm{R} / \mathrm{C} \\
& \mathrm{R}=\mathrm{Py} \times \mathrm{Y} \\
& \mathrm{C}=\mathrm{FC}+\mathrm{VC} \\
& \mathrm{a}=[(\mathrm{Py} \times \mathrm{Y}) /(\mathrm{FC}+\mathrm{VC})]
\end{aligned}
$$

dimana :

$\mathrm{R}=$ penerimaan

$\mathrm{C}=$ biaya

Py $=$ harga output

$\mathrm{Y}=$ output

$\mathrm{FC}=$ biaya tetap (fixed cost)

$\mathrm{VC}=$ biaya variabel (variabel cost)

Ada 3 (tiga) kemungkinan yang

diperoleh dari perbandingan antara
Penerimaan (R) dengan Biaya (C), yaitu : $\mathrm{R} / \mathrm{C}=1, \mathrm{R} / \mathrm{C}>1$ dan $\mathrm{R} / \mathrm{C}<1$, dengan rincian sebagai berikut:

$\mathrm{R} / \mathrm{C}=1$ keputusan hasil analisis (impas)

$\mathrm{R} / \mathrm{C}>1$ keputusan hasil analisis (untung)

$\mathrm{R} / \mathrm{C}<1$ keputusan hasil analisis (rugi)

Hasil analisis dan pengolahan data diperoleh data sebagai berikut:

Diketahui bahwa untuk varietas Pandanwangi diperoleh nilai $\mathrm{R} / \mathrm{C}$ rasio adalah sebesar 1,87 di dapatkan dari Total Penerimaan sebesar Rp. 12.000.000 lalu dibagi Total Biaya Rp. 6.430 .000 maka di dapatkan Nilai R/C Rasio sebesar 1,87. Menurut ketentuan jika R/C $>1$ keputusan hasil analisis (untung), berarti dapat disimpulkan bahwa hasil penelitian ini untuk usaha tani varietas Pandanwangi termasuk pada keputusan usaha yang menguntungkan.

\section{Analisis Pemasaran}

Saluran dan Lembaga Pemasaran di Kelompok Tani Bangkit

Menurut Kotler (2010) saluran pemasaran adalah sekelompok organisasi yang saling bergantung dan terlibat dalam proses pembuatan produk atau jasa yang disediakan untuk digunakan atau dikonsumsi. Saluran pemasaran merupakan seperangkat alur yang diikuti produk atau jasa setelah produksi, berakhir dalam pembelian dan digunakan oleh pengguna akhir.

Adapun jenis saluran saluran Pemasaran menurut Kotler dan Keller (2007) jumlah tingkat saluran pemasaran dibagi dalam empat jalur yang dapat dipakai produsen dalam menyalurkan produknya, yaitu :

1. Saluran nol-tingkat

Disebut saluran pemasaranlangsung, terdiri atas produsen yang langsung menjual kepada pelanggan akhir.

ANALISIS USAHATANI $r$ DAN
PEMASARAN BERAS PANDANWANGI
(STUDI KASUS DI KELOMPOK TANI
BANGKIT DESA BABAKAN KARET
KECAMATAN CIANJUR KABUPATEN
CIANJUR)


2. Saluran satu-tingkat

$$
\text { Mempunyai satu perantara }
$$
penjualan, seperti pengecer.

3. Saluran dua-tingkat

Mempunya dua perantara. Dalam pasar barang konsumsi, mereka umumnya adalah pedagang besar dan pengecer.

4. Saluran tiga-tingkat

Mempunyai tiga perantara, misalnya pedagang besar menjual ke pemborong, yang akan menjualnya beberapa pengecer kecil.

Lembaga pemasaran yang terlibat dalam pemasaran komoditas padi Pandanwangi dari Kelompok Tani Bangkit hanya ada 1 yaitu distributor. Pedagang besar atau distributor adalah pedagang yang membeli hasil pertanian dengan jumlah besar dari pedagang pengepul atau langsung dari petani. Modalnya relatif besar sehingga mampu memproses hasil pertanian yang dibeli. Lembaga pemasaran menjalankan fungsifungsi pemasaran di dalamnya sehingga komoditas Pandanwangi siap dikonsumsi oleh konsumen dan lembaga pemasaran ini berfungsi utuk mempermudah penyaluran komoditas Pandanwangi. Berikut adalah saluran pemasaran komoditas padi Pandanwangi. Disini Kelompok Tani Bangkit sebagai produsen langsung menjual Beras Pandanwangi ke distributor lalu distributor menjualnya ke konsumen langsung dan pasar modern (Transmart Carefour).

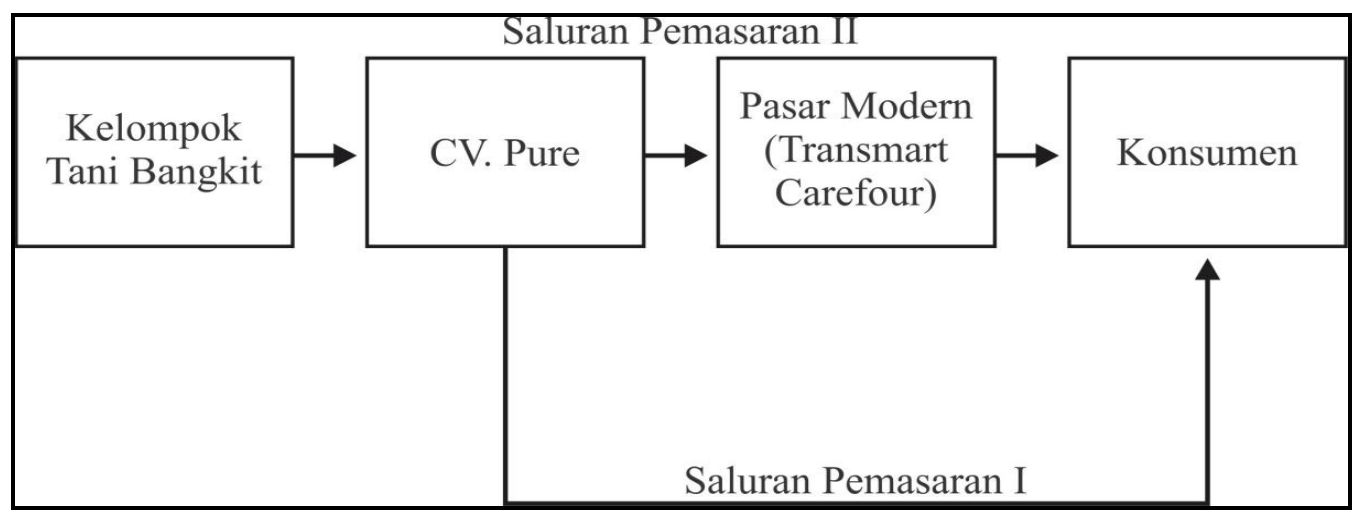

Gambar 1.Saluran Pemasaran Beras Pandanwangi.

Pada gambar di atas, saluran pemasaran komoditas Pandanwangi Kelompok Tani Bangkit terdapat 2 (dua) saluran pemasaran, yaitu: Saluran pemasaran ke-1 dari Kelompok Tani Bangkit - distributor (CV. Pure) konsumen. Saluran pemasaran ke-2 dari Kelompok Tani Bangkit - distributor (CV. Pure) - pasar modern (Transmart Carefour) - konsumen.

Berdasarkan 2 (dua) saluran pemasaran yang telah diketahui, distributor memiliki peran penting dalam tataniaga komoditas Pandanwangi di Kelompok Tani Bangkit karena volume penjualan ke distributor sangat besar.
Kedua saluran pemasaran tersebut dijelaskan sebagai berikut:

Saluran Pemasaran I (Saluran Pemasaran Satu Tingkat)

Saluran pemasaran pertama adalah saluran pemasaran satu tingkat, yang terdiri dari Kelompok Tani Bangkit distributor (CV. Pure) - konsumen. Pada saluran pemasaran ini Petani menjual Beras Pandanwangi kepada distributor, selanjutnya distributor menjual Beras Pandanwangi kepada konsumen.

Saluran Pemasaran II (Saluran Pemasaran Dua Tingkat)

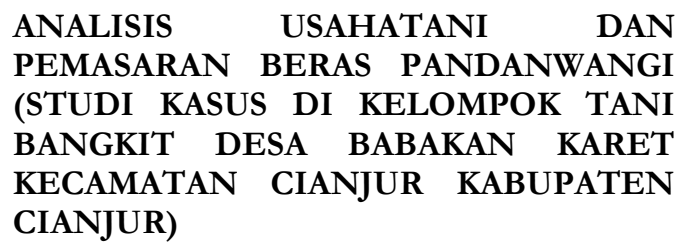


Saluran pemasaran kedua adalah saluran pemasaran dua tingkat, yang terdiri dari Kelompok Tani Bangkit distributor (CV. Pure) - pasar modern (Transmart Carefour). - konsumen. Pada saluran pemasaran ini petani menjual Beras Pandanwangi kepada distributor, selanjutnya distributor menjual Beras Pandanwangi kepada pasar modern kemudian pasar modern menjual langsung ke konsumen.

\section{Fungsi - Fungsi Pemasaran}

Kegiatan pasca panen yang dilakukan di Kelompok Tani Bangkit dari mulai panen sampai proses menjadi beras Pandanwangi maka Kelompok Tani Bangkit melakukan fungsi - fungsi pemasaran yang diantaranya adalah fungsi fisik dan fungsi pertukaran sebagai berikut:

1. Fungsi Fisik : Fungsi fisik yang dilakukan petani yaitu berupa penjemuran, penggilingan dan pengemasan.

$>$ Penjemuran : Petani melakukan kegitan penjemuran, penjemuran gabah kering ini dilakukan selama 2 hari jika cuaca cerah.

Penggilingan : di dalam proses penggilingan terdapat beberapa proses yang dilalui. Proses - proses itu adalah perontokan butiran padi dari malainya dan pemisahan butiran padi dari sekamnya.

Pengemasan : Pengemasaran yang dilakukan oleh petani hanya menggunakan karung, itu dikarenakan pengemasan menggunakan plastik berlabel dilakukan di tingkat distributor.

2. Fungsi Pertukaran : Fungsi pertukaran yang dilakukan oleh petani adalah penjualan.

$>$ Penjualan : Kegiatan penjualan yang dilakukan oleh petani kepada distributor adalah dalam bentuk beras.
Fungsi pemasaran yang dilakukan di tingkat distributor yang dalam hal ini adalah CV Pure dimana dalam proses pemasaran komoditas Pandanwangi yaitu melakukan fungsi pertukaran, fungsi fisik dan fungsi fasilitas sebagai berikut :

1. Fungsi Pertukaran : Distributor melakukan fungsi pertukaran melalui aktivitas pembelian dan penjualan beras Pandanwangi. Kegiatan yang dilakukan yaitu distributor membeli komoditas Pandanwangi dari petani dan menjual kembali beras Pandanwangi ke pasar modern dan konsumen langsung

2. Fungsi Fisik : Fungsi fisik yang dilakukan oleh distributor adalah pengangkutan dan bongkar muat

> Pengangkutan yang dilakukan distributor saat pengambilan ke petani dan saat pengiriman ke pasar modern (Transmart Carefour) yaitu dengan menggunakan mobil box. Distributor mengeluarkan biaya bongkar muat yakni mengangkut beras Pandanwangi. Biaya yang dikeluarkan berupa biaya angkut buruh dan transportasi.

3. Fungsi Fasilitas : Fungsi fasilitas yang dilakukan oleh distributor berupa sortasi, pengemasan dan penanggungan resiko.

> Sortasi : Sortasi dilakukan oleh CV Pure ketika beras Pandanwangi tidak terjual dalam kurun waktu 3 4 bulan, karena dapat mengurangi aroma dari beras Pandanwangi tersebut.

Pengemasan : Pengemasan yang baik dapat menjaga suatu produk dari kerusakan yang dapat menurunkan kualitas dan nilai jual produk. Pengemasan beras Pandanwangi yang dilakukan oleh distributor menggunakan kemasan plastik dengan ukuran $1 \mathrm{~kg}$ 2,5 kg, dan $5 \mathrm{~kg}$ serta sudah menggunakan label sertifikat indikasi geografis ( IG) yang menandakan bahwa

ANALISIS USAHATANI DAN
PEMASARAN BERAS PANDANWANGI
(STUDI KASUS DI KELOMPOK TANI
BANGKIT DESA BABAKAN KARET
KECAMATAN CIANJUR KABUPATEN
CIANJUR)


Pandanwangi ini murni dan asli dari daerah Cianjur.

Penanggungan Resiko : Resiko yag terdapat dalam pemasaran mencakup penurunan mutu dan kerusakan produk.

Margin Pemasaran dan B/C Rasio

Analisis margin pemasaran digunakan untuk melihat tingkat efisiensi. Margin pemasaran merupakan perbedaan harga yanga terjadi di tingkat produsen (harga jual) dengan harga di tingkat konsumen (harga beli). Margin pemasaran dihitung berdasarkan hasil pengurangan harga penjualan dengan harga pembelian pada setiap lembaga pemasaran (Limbong dan Sitorus.1987). Besarnya margin pemasaran dipengaruhi oleh jalur pemasaran komoditas bersangkutan. Margin pemasaran diperoleh dari lembaga pemasaran hasil dari fungsi-fungsi pemasaran, harga penjualan dan harga pembelian di setiap tingkatan lembaga pemasaran mulai dari petani, pengumpul, pedagang besar, pedagang pengecer, dan konsumen.

Saluran pemasaran yang ada di Kelompok Tani Bangkit yaitu:

1. Kelompok Tani Bangkit $\rightarrow$ CV. Pure $\rightarrow$ Konsumen

2. Kelompok Tani Bangkit $\rightarrow$ CV. Pure $\rightarrow$ Pasar modern (Transmart Carefour) $\rightarrow$ Konsumen

Harga, biaya, keuntungan, marjin dan $\mathrm{B} / \mathrm{C}$ ratio varietas Pandanwangi dari produsen sampai ke konsumen melalui saluran pemasaran I dan II di Kelompok Tani Bangkit disajikan dalam tabel 6 . 
Tabel 6.Marjin dan B/C Ratio pemasaran Beras Pandanwangi

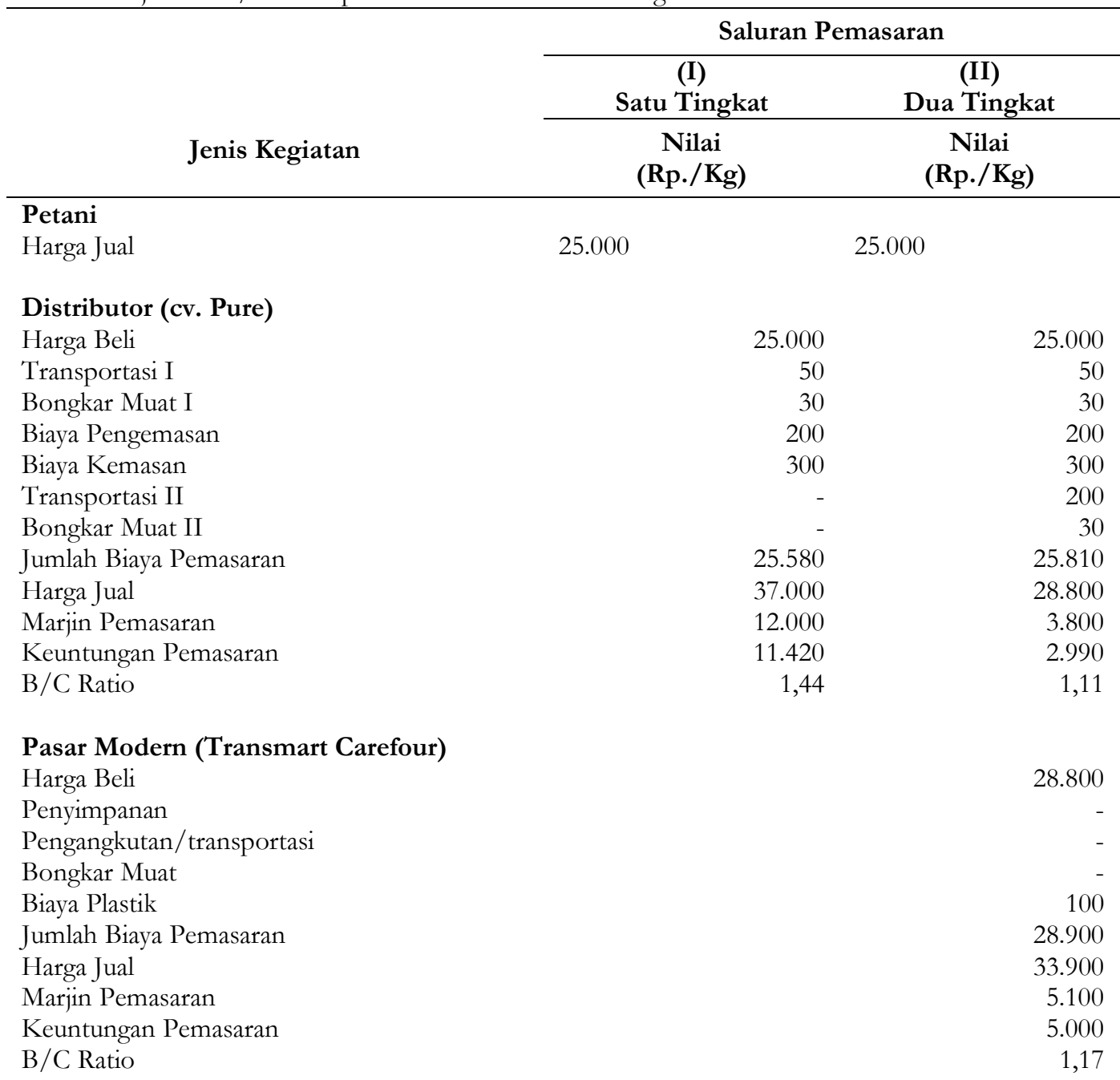

\begin{tabular}{lrr}
\hline $\begin{array}{l}\text { Harga masing - masing di Tingkat } \\
\text { Konsumen }\end{array}$ & I & II \\
\hline Harga di Tingkat Konsumen & 37.000 & 33.900 \\
\hline Marjin & 12.000 & 8.900 \\
\hline
\end{tabular}

Sumber: Data Primer (Diolah), 2018.

Farmer's Share

Tabel 7.Farmer's Share Pada Saluran Pemasaran Beras Pandanwangi di Kelompok Tani Bangkit

\begin{tabular}{cccc}
\hline Saluran Pemasaran & $\begin{array}{c}\text { Harga di Tingkat } \\
\text { Petani } \\
\mathbf{( R p )}\end{array}$ & $\begin{array}{c}\text { Harga di Tingkat } \\
\text { Konsumen } \\
(\mathbf{R p})\end{array}$ & Farmer's Share (\%) \\
\hline Saluran Pemasaran 1 & $25.000,-$ & $37.000,-$ & \\
Saluran Pemasaran 2 & $25.000,-$ & $33.900,-$ & 67,57 \\
& & & 73,75
\end{tabular}

Sumber: Data Primer (Diolah), 2018.

\begin{tabular}{l}
\hline ANALISIS USAHATANI DAN \\
PEMASARAN BERAS PANDANWANGI \\
(STUDI KASUS DI KELOMPOK TANI \\
BANGKIT DESA BABAKAN KARET \\
KECAMATAN CIANJUR KABUPATEN \\
CIANJUR)
\end{tabular}




\section{KESIMPULAN}

Berdasarkan hasil analisis, maka penulis menyimpulkan:

1. Usahatani padi Pandanwangi di Kelompok Tani Bangkit efisien dengan nilai $\mathrm{R} / \mathrm{C}$ rasio 1,87 . Dilihat dari nilai $\mathrm{R} / \mathrm{C}$ Rasio menurut ketentuan jika R/C $>1$ maka keputusan hasil analisis usahatani Pandanwangi dinyatakan (untung) atau layak untuk dijalankan usahatani tersebut.

2. Saluran pemasaran yang efisien adalah saluran pemasaran II meskipun nilai margin keuntungannya lebih kecil dari saluran pemasaran I, dikarenakan permintaan pasar jauh lebih tinggi dan mengingat hasil pertanian memiliki batas waktu tertentu (kadaluwarsa) maka diperlukan perputaran barang yang lebih cepat dan itu ada di saluran pemasaran II. Sedangkan Farmer's share yang paling efisien berada di saluran pemasaran II yaitu $73,75 \%$.

\section{DAFTAR PUSTAKA}

Antara, 2009. Pedoman Menyusun Rencana Usaba Agribisnis (Agribusiness Plan). Program Studi Agribisnis dan Ekonomi Pertanian. Denpasar: Universitas Udayana.

Arikunto, 2006. Prosedur Penelitian : Suatu Pendekatan Praktek. Jakarta : Rineka Cipta

Balai Besar Penelitian Tanaman Padi. 2012. Karakterisasi dan Standarisasi Mutu Gabah-beras.

Dinas Pertanian Kabupaten Cianjur. 2003. Usulan Pemutihan Varietas Padi Sawah

Pandan Wangi Cianjur. Pemerintah Propinsi Jawa Barat, Dinas Pertanian

Pertanian Kabupaten Cianjur. 2004. Laporan Tahunan Tahun
2004. Laporan. Dinas Pertanian

Kabupaten Cianjur. Cianjur.

Pertanian Kabupaten Cianjur. 2006. Laporan Tahunan Tahun 2006. Laporan. Dinas Pertanian Kabupaten Cianjur. Cianjur Pertanian Kabupaten Cianjur. 2011. Komoditas Unggulan Kabupaten Cianjur. Dinas Pertanian Kabupaten Cianjur, Cianjur.

Kotler, 2005. Manajemen Pemasaran Edisi Kesebelas Jilid1;Jakarta:PT. INDEKS.

2008. Manajemen Pemasaran, Edisi Milenium diterjemahkan Benyamin Molan, PT. Prenhallindo, Jakarta.

2010. Manajemen Pemasaran. Edisi tiga belas Bahasa Indonesia. Jilid 1 dan 2. Jakarta : Erlangga

Kotler, Philip. 2005. Manajemen Pemasaran Jilid 1. PT. Indeks. Jakarta

Kotler dan Keller, 2007. Manajemen Pemasaran, Edisi 12, Jilid 1, PT.Indeks, Jakarta.

Limbong dan Sitorus dalam Sudiyono, 2011. Analisis Efisiensi Pemasaran. - Fakultas Pertanian. Institut Pertanian Bogor. Bogor.

Limbong, W. H dan P. Sitorus. 1987. Pengantar Tataniaga Pertanain. Jurusan

Ilmu-Ilmu Sosial Ekonomi Pertanian. Fakultas Pertanian. Institut Pertanian Bogor. Bogor.

Mubyarto. 2003. pengantar ekonomi pertanian. LP3ES. Jakarta.

Nuhang, Iskandar A. 2003. Membangun Pertanian Masa Depan. Semarang: Aneka Ilmu..

Peraturan Daerah, 2012. Pelestarian dan Perlindungan Padi Pandanwangi Cianjur..

Prima Gandi. 2008. Skripsi Analisis Usahatani Dan Tataniaga Padi Varietas Unggul (Studi Kasus Padi Pandanwangi Di Kecamatan Warungkondang Kabupaten Cianjur).

ANALISIS USAHATANI DAN
PEMASARAN BERAS PANDANWANGI
(STUDI KASUS DI KELOMPOK TANI
BANGKIT DESA BABAKAN KARET
KECAMATAN CIANJUR KABUPATEN
CIANJUR)


Fakultas Pertanian, Insititut Pertanian Bogor. Bogor.

Rahim A, Hastuti RDR. 2008. Pengantar, teori dan kasus ekonometrika pertanian. Penebar Swadaya. Jakarta.

Rahim dan Hastuti, 2007. Pengantar, Teori, Lembaga Pemasaran. Jakarta : Penebar Swadaya.

2008. Ekonomika Pertanian (Pengantar, Teori, dan Kasus) Penebar Swadaya, Jakarta.

Saladin, 2003. Intisari Pemasaran dan Unsur - Unsur Pemasaran. Cetakan ketiga, Bandung : Linda Karya

Setioso, 2011.Pengertian Pemasaran. Bogor

Sudiyono, 2002. Pemasaran Pertanian.Universitas Muhammadiyah Malang. Malang.

Sudiyono, 2004. Pemasaran Pertanian. Edisi Kedua, UMM Press. Malang

Sudiyono A. 2011. Pemasaran Pertanian. Malang (ID): UMM Press.

Sugiyono, 2010. Metode Penelitian Pendidikan Pendekatan Kuantitatif, Kualitatif, dan R\&D. Bandung : ALFABETA.

2011. Metode Penelitian Kuantitatif, Kualitatif, dan R\&D. Bandung : AFABETA,cv.

2012. Metode Penelitian Kuantitatif, Kualitatif, dan R\&DD. Cetakan ke-17. Alfabeta. Bandung.

Soekartawi. 1993. Prinsip Dasar Ekonomi Pertanian. Raja Grafindo Persada. Jakarta.

Soekartawi, 2006. Analisis Usahatani. Penerbit Universitas Indonesia. UI Press Jakarta.

Stanton, 2004. Prinsip Pemasaran. Edisi Ketujuh Jilid Kesatu, Jakarta : Airlangga

Susenas-BPS. 2014. Buletin Konsumsi Pangan. Volume 5 No.1. Jakarta: Pusat Data dan Sistem Informasi Pertanian.
Swasta Manajemen Pemasaran Modern, Liberty : Yogyakarta, Irawan. 2012.

Tjiptono, 2008. Strategi Pemasaran. Edisi Ketiga, Andi, Yogyakarta.

Ubaydilah, Muhammad. 2008. Analisis Pendapatan dan Margin Pemasaran Padi Rumah Lingkungan Metode SRI (System of Rice Intensification) Kasus : Desa Ponggang Kecamatan Sagalaherang Kabupaten Subang, Jawa Barat. Progaram Studi Ektensi Manajemen Agribisnis. Fakultas Pertanian. Institut Pertanian Bogor. Bogor.

Usman, 2009. Metodologi Penelitian Sosial dan Ekonomi, CV. Alfabeta. Bandung.

Ustriyana, I.N.G. 2015. Agribusiness Model in Rural Community Economic: Indonesia Perspective. Vol.10(4), pp. 174-178. African Journal of Agricultural Research.

W.Y Stanton, 2012. Prinsip Pemasaran, Edisi Ketujuh, Jilid Kedua. Erlangga, Jakarta.

Yulianingsih, R. 2012. Pengujian Mutu Beras. Balai Besar Penelitian Tanaman Padi. Sukamandi.

\begin{tabular}{|c|c|}
\hline USAHATANI & ASEP SAEPUL ALAM dan MUH HERI KHOERUDIN \\
\hline PEMASARAN BERAS PANDANWANGI & \\
\hline (STUDI KASUS DI KELOMPOK TANI & \\
\hline BANGKIT DESA BABAKAN KARET & \\
\hline $\begin{array}{l}\text { KECAMATAN CIANJUR KABUPATEN } \\
\text { CIANIUR) }\end{array}$ & \\
\hline
\end{tabular}

